\title{
Ongoing production of low-fitness hybrids limits range overlap between divergent cryptic species
}

\author{
Else K. Mikkelsen ${ }^{1,2 *}$ \& Darren Irwin ${ }^{1}$ \\ ${ }^{1}$ Department of Zoology, and Biodiversity Research Centre, University of British Columbia, Canada, 6270 University Blvd., \\ Vancouver BC, V6T 1 Z4 \\ ${ }^{2}$ Department of Ecology \& Evolutionary Biology, University of Toronto, Canada, 1265 Military Trail, M1C 1A4 \\ * Correspondence: else.mikkelsen@mail.utoronto.ca
}

\begin{abstract}
$\underline{\text { Abstract }}$
Contact zones between recently-diverged taxa provide opportunities to examine the causes of reproductive isolation and to examine the processes that determine whether two species can coexist over a broad region. The Pacific Wren (Troglodytes pacificus) and the Winter Wren (Troglodytes hiemalis) are two morphologically similar songbird species that started diverging about 4 million years ago, older than most sister species pairs. The ranges of these species come into narrow contact in western Canada, where the two species remain distinct in sympatry. To assess evidence for differentiation, hybridization, and introgression in this system, we examined variation in over 250,000 single nucleotide polymorphism markers distributed across the genomes of the two species. The two species formed highly divergent genetic clusters, consistent with long-term differentiation. In a set of 75 individuals from allopatry and sympatry, two first-generation hybrids (i.e., F1's) were detected, indicating only moderate levels of assortative mating between these taxa. We found no recent backcrosses or F2's or other evidence of recent breeding success of F1 hybrids, indicating very low or zero fitness of F1 hybrids. Examination of genomic variation shows evidence for only a single backcrossing event in the distant past. The sizeable rate of hybridization combined with very low fitness of F1 hybrids is expected to result in a population sink in the contact zone, largely explaining the narrow overlap of the two species. If such dynamics are common in nature, they could explain the narrow range overlap often observed between pairs of closely related species. Additionally, we present evidence for a rare duplication of a large chromosomal segment from an autosome to the $\mathrm{W}$ chromosome, the female-specific sex chromosome in birds.
\end{abstract}

Keywords: Hybridization, Speciation, Troglodytes, Translocation, Reproductive isolation

\section{Introduction}

One of the foundational goals of evolutionary biology is to understand the mechanisms at play as one species splits into two. A major debate in the speciation literature (e.g., Mayr, 1942; Price, 2008) has centred on the relative importance of assortative mating (i.e., premating isolation) and low hybrid fitness (i.e., postzygotic isolation). An often-articulated view is that premating isolation is most important during early stages of the speciation process, with postzygotic isolation building later (Mayr, 1942; Grant \& Grant, 1997; Schumer et al., 2017). Also debated is how important geographic separation of populations (i.e., allopatry) is in causing speciation, versus the possibility of sympatric speciation or speciation-with-gene-flow (e.g., Nosil, 2008). An often-observed pattern of closely related species occurring in neighbouring geographic regions with just a small region of overlap implies that some process prevents coexistence between species. This restricted overlap is often interpreted to be a result of differential specialization to distinct habitats that change across space, and/or niche exclusion, in which species are so similar they compete for the same resources (Price \& Kirkpatrick, 2009; Lee-Yaw \& Irwin, 2015). Hybridization and/or reproductive interference can also limit range overlap between closely related species (Barton \& Hewitt, 1989; Gröning \& Hochkirch, 2008). Close examination of the overlap zone between closely related species can provide insight into the strength and causes of reproductive isolation as well as the reasons for limited range overlap.

Recent advancements in DNA sequencing technology (Elshire et al., 2011; Goodwin, McPherson, \& McCombie, 2016; Heather \& Chain, 2016) have enabled the detection of differentiation, hybridization, and genetic introgression between diverging species (Payseur \& Rieseberg, 2016). Genotyping-by-sequencing (GBS; Elshire et al. 2011) allows for many individuals to be simultaneously genotyped at tens or hundreds of thousands of genetic loci, providing genome-wide information about genetic relationships and individual ancestry. With GBS data, patterns of allele frequency differentiation and nucleotide sequence divergence can be compared between populations across a broad sample of the genome, and individuals with hybrid ancestry can be identified. More ancient processes of isolation of populations, gene flow, and adaptive introgression can be inferred by examining relationships between relative differentiation $\left(F_{\mathrm{ST}}\right)$, absolute between-population genetic distances $\left(\pi_{\mathrm{B}}\right.$, also known as $\left.D_{\mathrm{xy}}\right)$, and within-population genetic diversity $\left(\pi_{\mathrm{W}}\right)$ (Cruickshank \& Hahn 2014; Irwin et al. 2016, 2018).

The Pacific Wren (Troglodytes pacificus) and Winter Wren (Troglodytes hiemalis) are two closely-related songbirds that provide an interesting case of a narrow contact zone between two similar-looking species that started diverging in the distant past. These two species were previously considered conspecific along with the Eurasian Wren (Troglodytes troglodytes), but in 2010 they were designated as separate species (Chesser et al., 2010) based on maintenance of substantial genetic and song differentiation in an overlap area in northeastern British Columbia (BC), Canada (Toews \& Irwin, 2008). The existence of cryptic species in this system had been first suggested by song differentiation between the populations (Kroodsma \& Momose, 1991). While extremely variable, songs of Pacific Wrens in western North America were markedly different than those of Winter Wrens in eastern North America, the latter of which was more similar to songs across Eurasia. This pattern was later reflected in mitochondrial DNA sequences, which showed three major wren clades, with Winter Wrens being more similar to Eurasian Wrens than they were to Pacific Wrens (Drovetski et al., 2004). Toews and Irwin (2008) assessed nuclear DNA differentiation by using 90 Amplified Fragment Length Polymorphism (AFLP) markers and these showed strong differentiation between the 
Pacific and Winter Wrens, both in allopatry and within the narrow contact zone in northeastern BC. One likely first-generation hybrid was identified by this study (Toews \& Irwin, 2008), but the limitations of AFLP data made it difficult to confirm this identity with confidence.

While most temperate songbird species pairs have been estimated to have diverged within the last one million years (Weir \& Schluter, 2007), the mitochondrial divergence of Pacific and Winter Wren appears remarkably old, estimated at 4.3 million years ago (Toews \& Irwin, 2008) using a standard molecular clock of $2 \%$ sequence divergence per million years (Weir \& Schluter, 2008). These wrens provide an intriguing opportunity to glimpse the genomic patterns of differentiation in an older species pair with greater reproductive isolation than many recently-studied bird taxa (e.g., Morales et al., 2016; Baldassarre, White, Karubian, \& Webster, 2014; Toews et al., 2016; Brelsford \& Irwin 2009).

In this study we use genotyping-by-sequencing to assess evidence for differentiation, hybridization, and introgression across the genomes of Pacific and Winter Wrens, from regions of both allopatry and sympatry in North America (Figure 1A). Using variation at hundreds of thousands of SNPs distributed through the genome, we ask: 1) How differentiated are Pacific and Winter Wrens, in terms of both relative differentiation and genetic distance?; 2) Is there hybridization between the species, and what classes of hybrids are present (e.g., F1, F2, backcross)?; and 3) Is there evidence for past introgression between the species? We use answers to these questions to infer the relative importance of assortative mating and low hybrid fitness in speciation of these wrens. Our findings provide substantial insight into why there is not more overlap in breeding range between the two species. These conclusions are likely relevant to the dynamics of many contact zones between closely related species.

While it was not the primary purpose of this study, we additionally demonstrate how comparisons of GBS data between females and males can be used to identify interchromosomal translocations between autosomes and sex chromosomes, and we document one of the few known examples in birds.

\section{$\underline{\text { Methods }}$}

\section{Sample Collection}

We used DNA samples from a total of 76 Pacific and Winter Wrens in this study, including 43 wrens from the allopatric range of the Pacific Wren, 22 from sympatry in Tumbler Ridge BC, and 11 from the allopatric range of the Winter Wren. Sampling locations are summarized in Table S1, and information from each individual can be found in Table S2. Most samples analyzed in this study were collected previously for AFLP analysis by Toews \& Irwin (2008). Wrens were attracted by song playback and temporarily captured using mist-nets, and blood samples were taken from the brachial vein and stored in Queen's Lysis Buffer (Seutin, White, \& Boag, 1991). A Marsh Wren (Cistothorus palustris) from Vancouver, BC was included for use as an outgroup. Cistothorus is thought to belong to the sister group of the Winter Wren complex (Barker, 2017; Gomez, Barber, \& Peterson, 2005; Mann, Barker, Graves, Dingess-Mann, \& Slater, 2006), with an estimated divergence time of 5 million years ago (Barker, 2017).

\section{GBS Library Preparation}

DNA samples were extracted from whole blood or tissues using a standard phenol-chloroform extraction procedure. Original DNA extracts previously prepared for AFLP analysis (Toews \& Irwin, 2008) were available for most samples, and these were supplemented by reextracted DNA when required to achieve $100 \mathrm{ng}$ DNA per sample. We measured DNA concentrations with a Qubit fluorometer (Invitrogen), and diluted or re-concentrated samples to $20 \mathrm{ng} / \mu \mathrm{L}$ in TE buffer.

Samples were genotyped using genotyping-by-sequencing (GBS), described by Elshire et al. (2011) with modifications by Alcaide, Scordato, Price, and Irwin (2014). This method is based on sequencing a library of size-selected amplified DNA fragments that are from sequences adjacent to restriction enzyme recognition sites throughout the genome. Fragments from each individual are labelled with a unique barcode, allowing them to be pooled, sequenced, and then sorted by individual. This method can produce a dataset of many thousands of SNPs throughout the genome.

We digested $100 \mathrm{ng}$ of DNA of each sample using PstI restriction endonuclease (New England Biolabs), and then ligated fragment ends to common and barcode adapters. A no-barcode blank and a no-DNA blank were run alongside the samples as negative controls. Samples were purified using AMPure XP Beads (Beckman-Coulter) at a ratio of 23:15 in order to eliminate fragments smaller than $100 \mathrm{bp}$. We amplified the fragments via PCR with Phusion High-fidelity Taq polymerase (New England Biolabs), with the following protocol: $98^{\circ} \mathrm{C}$ $(30 \mathrm{sec})$ followed by 18 cycles of $98^{\circ} \mathrm{C}(10 \mathrm{sec}), 65^{\circ} \mathrm{C}(30 \mathrm{sec})$, and $72^{\circ} \mathrm{C}(30 \mathrm{sec})$, with a final extension step at $72^{\circ} \mathrm{C}(5 \mathrm{~min})$. See Figure $\mathrm{S} 1$ for primer sequences. PCR was performed separately on each sample prior to pooling in order to achieve more uniform coverage of each sample in the pooled library. Concentrations of PCR products were fluorometrically assayed, and the library was pooled with $100 \mathrm{ng}$ of each sample and control. The DNA was then concentrated in a vacuum centrifuge. We ran the library in three lanes of a $2 \%$ agarose gel and extracted the 300-400 bp fragments using a QIAquick Gel Extraction Kit (Qiagen) following the manufacturer's instructions. The final library was diluted to a concentration of $2 \mathrm{ng} / \mu \mathrm{L}$ in $50 \mu \mathrm{L}$. The size range of the fragments was examined using a Bioanalyzer, and the library was sequenced using one lane of Illumina HiSeq 2500 at the Genome Quebec Innovation Centre. This generated paired-end 125 bp reads.

\section{Bioinformatics Pipeline}

We demultiplexed and removed barcode and adapter sequences according to the methods used by Irwin, Alcaide, Delmore, Irwin, and Owens (2016), allowing no barcode sequence mismatches. Reads were trimmed using TRIMMOMATIC v0.32 (Bolger, Lohse, \& Usadel, 2014) with the following settings: Trailing:3, Slidingwindow:4:10, and Minlen:30. This trims the 3' end of reads where average base quality drops below 10 within a four-base sliding window, removes trailing bases below a quality of 3, and retains reads at least 30 bases in length. Reads were mapped to the Ficedula albicollis reference genome version 1.5 (Ellegren et al., 2012) using BWA-MEM v0.7.17 (Li \& Durbin, 2009), and the resulting SAM files were converted to BAM format using Picard v1.97 (http://broadinstitute.github.io/picard/). The singleend and paired-end BAM files were merged using Samtools (Li et al., 2009). Single nucleotide polymorphisms (SNPs) were identified using GATK v4.0.1.0 (McKenna et al., 2010) HaplotypeCaller, with max alternate alleles set to 2. We used VCFtools (Danecek et al., 2011) to remove indels, SNPs with more than two alleles, SNPs with more than $30 \%$ missing genotypes (max-missing $=0.7$ ), sites with mapping quality (MQ) below 20.0, and sites with heterozygosity above $60 \%$. This produced a GVCF file for each chromosome containing the genotypes of each individual. 


\section{Principal Components Analysis}

We used Principal Components Analysis (PCA) to visualize patterns of genetic clustering in the genotype dataset in $R$ (v1.1.383) (R Core Team, 2018) with custom R scripts by Irwin et al. (2016, 2018) using the package PCAMETHODS to impute missing data with svdImpute (Stacklies, Redestig, Scholz, Walther, \& Selbig, 2007). We excluded loci where the minor allele was observed only once (i.e., minor allele count $<2$ ) and then conducted PCA for each chromosome individually. A closely-related pair of $T$. pacificus individuals was detected and one individual of the pair was excluded (Table S2) to avoid the PCA being heavily influenced by that close relationship. PCA was then repeated for Pacific Wrens and Winter Wrens separately to investigate population structure within each species, and to investigate if the samples in the range of the subspecies Troglodytes pacificus salebrosus in southeastern $\mathrm{BC}$ and central Washington could be genetically distinguished from nominate $T$. $p$. pacificus samples.

\section{STRUCTURE Analysis}

To objectively assign individuals to populations and to further investigate levels of introgression, 20,000 of 127,778 phylogenetically informative SNPs (i.e., SNPs in which the minor allele was observed in more than one individual) were selected to analyze in STRUCTURE (v2.3.4) (Stephens, Pritchard, \& Donnelly, 2000). SNPs were randomly selected within each chromosome, with the representation of each chromosome proportional to the number of mapped SNPs it contained. STRUCTURE separates samples into populations by minimizing the linkage and Hardy-Weinberg disequilibrium between alleles within populations, and assigns a proportion of each individual's genome to each population. Analyses were run with the Admixture Model and assumption of correlated allele frequencies, with 100,000 Markov Chain Monte Carlo steps after a burn-in period of 100,000 steps. Simulations were run with ten replicates each from $K=1$ to $K=5$ populations. The optimal number of populations was identified by Structure Harvester (Earl \& vonHoldt, 2012) using the Evanno method (Evanno, Regnaut, $\&$ Goudet, 2005), which maximizes the rate of change in the log likelihood of the data $(\Delta K)$ given a simulated number of populations. Results from each run for the optimal $K$ were then combined using the FullSearch algorithm of CLUMPP (v1.1.2) (Jakobsson \& Rosenberg, 2007) and plotted using DISTRUCT (v1.1) (Rosenberg, 2004).

\section{Phylogenetic Network}

To examine the phylogenetic relationships and possible patterns of reticulation between lineages, a phylogenetic network was constructed using SplitsTree (v4.14.6) (Huson \& Bryant, 2006). This approach was chosen to reflect the possibility of net-like patterns of relatedness within species and between hybridizing lineages, which may not be reflected in a single bifurcating tree, since portions of each individual's genome will be inherited with recombination from many different ancestors. Distances were calculated using the UncorrectedP method, and a split network was formed using the NeighbourNet method and drawn with the Rooted EqualAngle algorithm. The Marsh Wren sample was used as an outgroup to root the tree.

\section{Patterns of Differentiation across the Genome}

To visualize patterns of differentiation and genetic distance across the genome, we plotted $F_{\mathrm{ST}}$ (allele frequency differentiation), $\pi_{\mathrm{B}}$ (betweenspecies sequence distance; sometimes referred to as $D_{\mathrm{xy}}$ ), and $\pi_{\mathrm{W}}$ (within-species sequence diversity) for sliding windows each containing 10,000 bases of mapped sequences across each chromosome. Note that each 10,000 base window represents a much larger unsequenced distance of the chromosome. Plotting $F_{\mathrm{ST}}$ allows for the identification of regions with fixed or nearly fixed allele differences between populations; such regions of elevated differentiation can be caused by selective sweeps along with restricted gene flow. Pairwise sequence distances $\pi_{\mathrm{W}}$ and $\pi_{\mathrm{B}}$ are the average proportions of nucleotides that differ between homologous sequences from the same $\left(\pi_{\mathrm{W}}\right)$ or different $\left(\pi_{\mathrm{B}}\right)$ populations. This can help to distinguish among several models for the formation of regions of high $F_{\mathrm{ST}}$ (Cruickshank \& Hahn 2014; Irwin et al. 2016, 2018). A pattern of regions of high $F_{\mathrm{ST}}$ having high $\pi_{\mathrm{B}}$ is consistent with incompatibility loci restricting gene flow in specific regions of the genome. In contrast, high $F_{\mathrm{ST}}$ regions having low $\pi_{\mathrm{B}}$ is consistent with selective sweeps across hybrid zones, followed by differentiation (Delmore et al. 2015; Irwin et al. 2016, 2018). Calculation of $\pi_{\mathrm{W}}$ and $\pi_{\mathrm{B}}$ incorporated both variant and invariant sites. Plots were created using custom R scripts by Irwin et al. $(2016,2018)$. $F_{\text {ST }}$ was calculated using the Weir \& Cockerham (1984) method, and the following equations were used:

$\pi_{W}=\frac{2 N}{2 N-1} 2 p(1-p)$

$\pi_{B}=p_{1}\left(1-p_{2}\right)+p_{2}\left(1-p_{1}\right)$

$F_{S T}=\frac{s^{2}-\left(\frac{\bar{p}(1-\bar{p})}{2 \bar{n}-1}-\frac{s^{2}}{4 \bar{n}-2}\right)}{\left(1-\frac{2 \bar{n} C^{2}}{2(2 \bar{n}-1)}\right) \bar{p}(1-\bar{p})+\left(1+\frac{2 \bar{n} C^{2}}{2(2 \bar{n}-1)}\right) \frac{s^{2}}{2}}$

where $s^{2}=\frac{n_{1}\left(p_{1}-\bar{p}\right)^{2}+n_{2}\left(p_{2}-\bar{p}\right)^{2}}{\bar{n}}$

and $\mathrm{C}=\frac{\sqrt{\left(n_{1}-\bar{n}\right)^{2}+\left(n_{2}-\bar{n}\right)^{2}}}{\bar{n}}$ for two populations with allele

frequencies $p_{1}$ and $p_{2}$ and sample sizes $n_{1}$ and $n_{2}$, with means $\bar{p}$ and $\bar{n}$. 
bioRxiv preprint doi: https://doi.org/10.1101/2021.02.09.430089; this version posted February 10, 2021. The copyright holder for this preprint (which was not certified by peer review) is the author/funder. All rights reserved. No reuse allowed without permission.

Mikkelsen \& Irwin, 08 Feb 2021 - preprint copy - BioRxiv

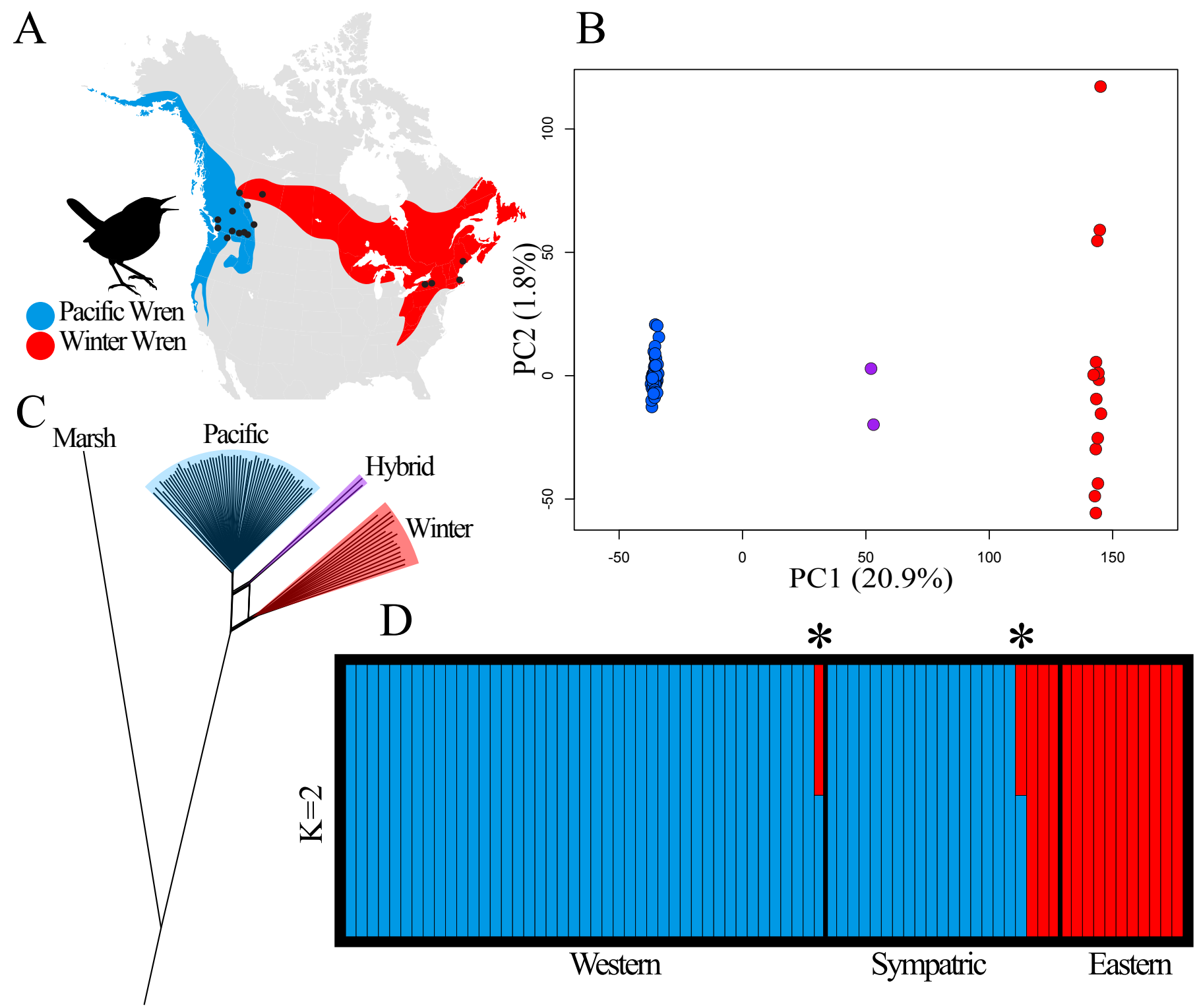

Figure 1. Genetic differentiation of Pacific and Winter Wrens. A: range of the Pacific (blue) and Winter (red) Wrens in North America. Sampling localities are indicated by black dots. B: Principal Components Analysis. Along the first major axis of variation (PC1), two distinct clusters correspond to Pacific (blue) and Winter Wrens (red), with two intermediate individuals inferred to be hybrids (purple). C: Phylogenetic network showing two clades of Pacific (blue) and Winter Wrens (red). The two hybrids (purple) are placed at an intermediate position with ancestry from both parental clades. A Marsh Wren (Cistothorus palustris) forms the outgroup. D: STRUCTURE analysis with $K=2$ populations assigns proportions of each sample to two populations, which correspond to Pacific (blue) or Winter Wren (red). All non-hybrid samples show 100\% assignment to one population. Two hybrids (asterisks) show intermediate population assignment between Pacific and Winter Wren, with 52\% and 48\% assignment respectively, which together with high heterozygosity is indicative of them being F1 hybrids.

\section{$\underline{\text { Results }}$}

\section{Sequencing results}

Sequencing produced 256,467,008 reads totalling $64.12 \mathrm{~Gb}$ from 77 individuals (the 76 Pacific or Winter Wrens, and the one Marsh Wren). One sample from Tumbler Ridge generated few reads and was discarded from analysis (Table S2). The filtered sequences altogether mapped to a total of $12.156 \mathrm{Mb}$ of the Ficedula genome, which represents $1.2 \%$ of the genome assembly (Kawakami et al., 2014). A total of 272,350 SNPs were identified within the Pacific/Winter Wren sample set, for an average of 260 SNPs per megabase. Of these, 144,572 were singletons and 127,778 had minor alleles that were found in more than one individual. An additional 62,819 fixed differences were found between Pacific/Winter Wrens and our Marsh Wren individual (the outgroup), and 681,753 between all of these wrens and the Ficedula reference genome. The distribution of SNPs among Ficedula chromosomes is summarized in Table S3. 
Mikkelsen \& Irwin, 08 Feb 2021 - preprint copy - BioRxiv

\section{Principal Components Analysis}

Principal components analysis (PCA) revealed two highly distinct genotypic clusters corresponding to Pacific and Winter Wrens widely separated along PC1 (Figure 1B), consistent with previous observations of strong differentiation between the two species in both mitochondrial DNA (Drovetski et al., 2004) and nuclear AFLP markers (Toews \& Irwin, 2008). Two individuals, one from Tumbler Ridge $\mathrm{BC}$ and one from Gavin Lake BC, were centred between the two clusters on PC1, a pattern expected for F1 hybrids between Pacific and Winter Wrens. The bird from Gavin Lake was previously identified as a possible hybrid by AFLP analysis, although this was considered speculative given the limitations of AFLP data (Toews \& Irwin, 2008). Our GBS data showed these two birds repeatedly having intermediate placement on PCAs of each chromosome (Figure S2) and consistent heterozygosity at highly differentiated SNPs along each chromosome, strongly indicating that these are F1 hybrids (later-generation hybrids would show a more variable pattern of inheritance across chromosomes through recombination of parental genotypes). No other intermediate birds appeared on PCAs of any chromosome, indicating that aside from the two F1 hybrids there were no other recent-generation hybrids or backcrosses in our sample. One Winter Wren individual from Tumbler Ridge did fall slightly outside of the Winter Wren cluster on chromosome 24; this individual was heterozygous for a short introgressed region and is discussed further below. For most chromosomes, PC1 separated Pacific and Winter Wrens, while PC2 captured variation within populations; Winter Wrens showed a greater spread of variation along PC2 than Pacific Wrens on most chromosomes, consistent with higher heterozygosity and nucleotide diversity $\left(\pi_{\mathrm{W}}\right.$; Table 2$)$, but this was not geographically structured variation.

Table 2. Patterns of differentiation and divergence between Pacific and Winter Wrens. $F_{\mathrm{ST}}, \pi_{\mathrm{B}}$, and $\pi_{\mathrm{W}}$ are averaged across autosomal windows, and are calculated for all windows as well as for the top $5 \%$ and $1 \%$ of windows with the highest $F_{\text {ST. }}$.

\begin{tabular}{llll}
\hline Statistic & $\begin{array}{l}\text { Genome-wide } \\
\text { Average }\end{array}$ & $\begin{array}{l}\text { Top 5\% } \\
\text { Differentiated } \\
\text { Windows }\end{array}$ & $\begin{array}{l}\text { Top 1\% } \\
\text { Differentiated } \\
\text { Windows }\end{array}$ \\
\hline$F_{\mathrm{ST}}$ & 0.31 & 0.54 & 0.74 \\
$\pi_{\mathrm{B}}$ & 0.00392 & 0.00365 & 0.00370 \\
$\pi_{\mathrm{W}}($ T. pacificus $)$ & 0.00264 & 0.00107 & 0.00062 \\
$\pi_{\mathrm{W}}($ T. hiemalis $)$ & 0.00333 & 0.00161 & 0.00095 \\
\hline
\end{tabular}

Principal components analysis within each species revealed no evidence for strong population structure within our sample of either Pacific or Winter Wrens. Pacific Wrens from southeastern British Columbia and central Washington (subspecies T. pacificus salebrosus) appeared interspersed with Pacific Wrens of the nominate Troglodytes pacificus pacificus, and could not be clearly distinguished by PCA of any chromosome using this dataset (Figure S3A). Similarly, no geographic structure appeared in a PCA of the Winter Wrens, with East Coast birds interspersed with the Albertan and British Columbian samples (Figure S3B).

\section{STRUCTURE Analysis}

STRUCTURE analysis with $K=2$ populations mirrored the results given by PCA, assigning most individuals to Pacific Wren or Winter Wren clusters with $100 \%$ confidence. The only exceptions were the two hybrids, which both showed intermediate proportions of 52\% Pacific Wren and 48\% Winter Wren (Figure 1D). Structure Harvester identified $K=2$ populations as optimal for this dataset using the Evanno Method.

\section{Phylogenetic Network}

Pacific and Winter Wrens formed two distinct clades in a phylogenetic network, with shallower divergences within species (Figure 1C). The two hybrids were placed at an intermediate position with ancestry from both the Pacific and Winter Wren clusters. Relative distances between taxa are given in Table 1. Pacific Wrens showed less within-group variation than Winter Wrens, consistent with a narrower spread on the PCA. The distance between the Pacific and Winter Wren clades was 1.38 times wider than the average distance between Pacific Wrens, while the distance between the Marsh Wren and Pacific Wrens was 2.64 times wider than the distance between Pacific and Winter Wrens.

Table 1. Relative distances between taxa calculated from a SplitsTree matrix of distances between individuals. Distances were standardized by the average distance between Pacific Wren individuals, and are proportional to the number of SNP differences between individuals. Standard deviations are given in parentheses.

\begin{tabular}{llll} 
& T. pacificus & T. hiemalis & C.palustris \\
\hline T. pacificus & $1(0.02)$ & $1.62(0.03)$ & $4.28(0.01)$ \\
T. hiemalis & & $1.38(0.03)$ & $4.34(0.02)$ \\
\hline
\end{tabular}

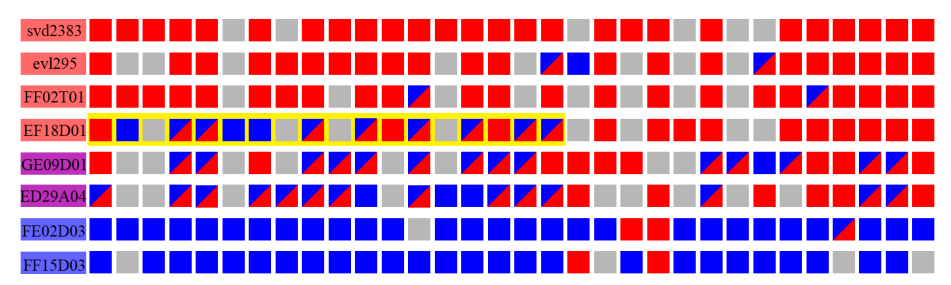

Figure 2. Introgression of a short Pacific Wren haplotype block into a Winter Wren. The first 32 alleles on chromosome 24 with $F_{\text {ST }}$ greater than 0.9 are plotted for eight representative individuals, showing either the Winter Wren-associated alleles (red blocks), Pacific-associated alleles (blue blocks), heterozygotes (red and blue triangles), or missing data (grey). Winter Wrens are homozygous for the red allele at most loci, while Pacific Wrens are homozygous for the blue allele at most loci and the two F1 hybrids (GE09D01 and ED29A04) are heterozygous at most of the loci. One Winter Wren, EF18D01, contains a Pacific-associated allele at 11 of the first 18 loci (gold highlight), while all other Winter Wrens contain a maximum of 1 Pacific-associated allele at these loci.

\section{Limited Introgression Despite Hybridization}

To detect historical introgression events that have led to some individuals of one species having genomic segments from the other species, the genotypes of every individual were plotted across each chromosome for all SNPs with $F_{\mathrm{ST}}$ higher than 0.9 between Pacific and Winter Wrens (Figure S7). A total of 3512 SNPs met this threshold, for an average of 3.4 markers per $\mathrm{Mb}$ (note that these are not uniformly distributed, leading to some stretches of lower or higher marker density). At these high- $F_{\mathrm{ST}}$ loci, Pacific and Winter Wrens are near fixation for different alleles, such that most samples are homozygous for a species-specific allele, while F1 hybrids are heterozygous at most loci. Introgressed regions were identified by eye as stretches of heterozygosity spanning at least five consecutive SNPs in an individual, where nearly all other members of the species are homozygous for a species-specific allele. This method should identify any large introgressed haplotype blocks that span multiple informative SNPs (i.e. $>1.5 \mathrm{Mb}$ on average, proportional to SNP density), but would miss very small haplotype blocks that have been broken by many generations of recombination and no longer span multiple informative SNPs. Despite a dataset of many informative SNPs across each chromosome, only one 
bioRxiv preprint doi: https://doi.org/10.1101/2021.02.09.430089; this version posted February 10, 2021. The copyright holder for this preprint (which was not certified by peer review) is the author/funder. All rights reserved. No reuse allowed without permission.

Mikkelsen \& Irwin, 08 Feb 2021 - preprint copy - BioRxiv

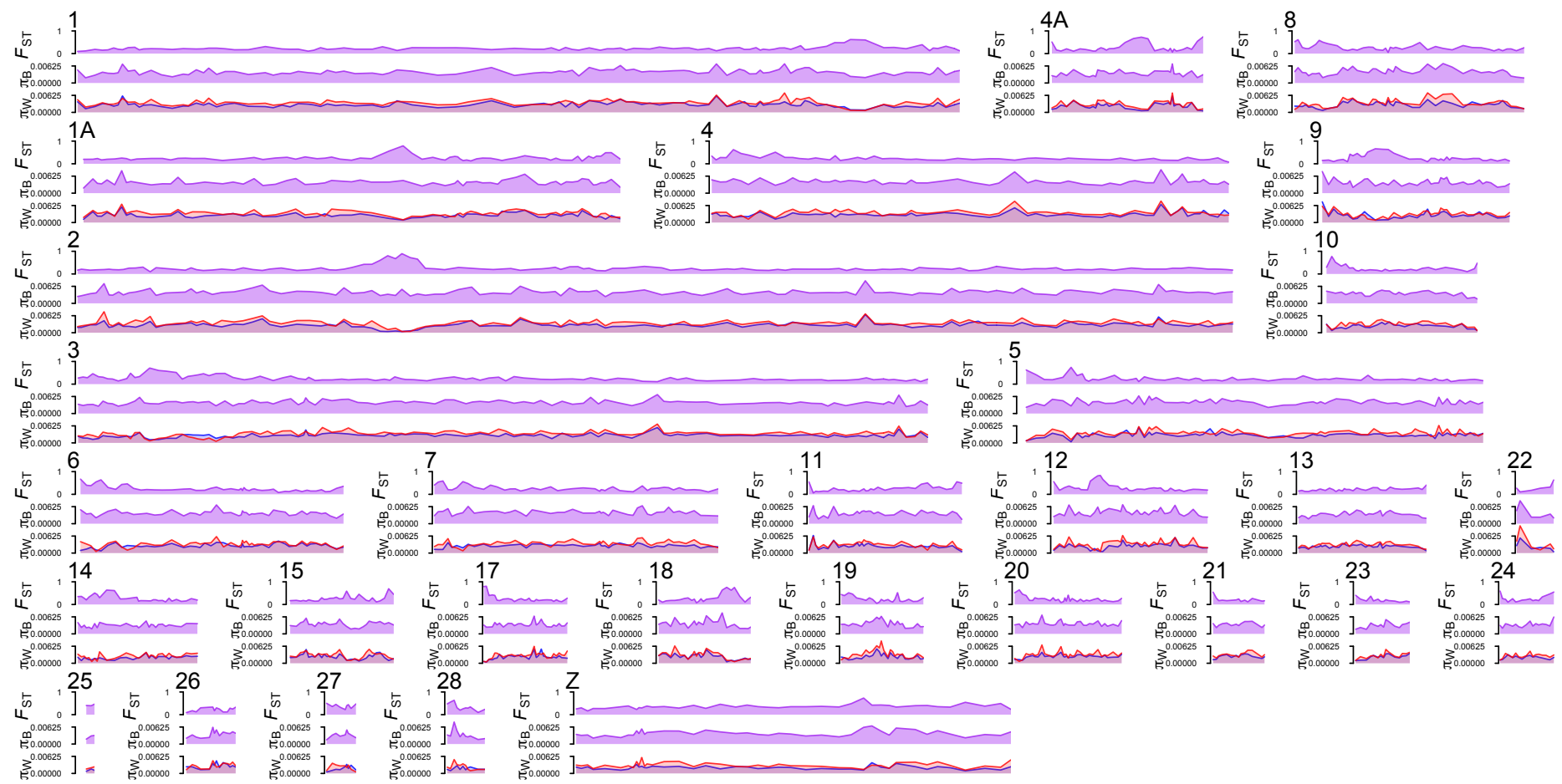

Figure 3. Peaks of divergence and differentiation across the genome. Each chromosome is plotted with windowed $F_{\mathrm{ST}}$ (allele frequency differentiation, top) and $\pi_{\mathrm{B}}$ (between-species pairwise sequence divergence, middle) between Pacific and Winter Wrens, as well as $\pi_{\mathrm{w}}$ (within-species pairwise sequence diversity, bottom) for Pacific (blue) and Winter Wrens (red).

introgressed haplotype block in a single individual was detected (Figure 2, Figure S7), spanning approximately the first $375,000 \mathrm{bp}$ of chromosome 24, corresponding to less than 5 centimorgans on the Ficedula genetic map (Kawakami et al., 2014). This individual was a Winter Wren from sympatry near Tumbler Ridge, BC, which contained a Pacific Wren-associated allele at 11 out of 18 high- $F_{\mathrm{ST}}$ SNPs in this genomic region (other Winter Wrens contained only $0-1$ out of 18 Pacific-associated alleles, and the two hybrids contained 9 and 14 out of the 18 Pacific-associated alleles). Given the small size of the remaining pacificus haplotype block within this individual, the hybridization event which gave rise to the introgressed region likely ocurred many generations in the past.

\section{Patterns of Differentiation Across the Genome}

To examine patterns of differentiation across the genome, $F_{\mathrm{ST}}, \pi_{\mathrm{B}}$, and $\pi_{\mathrm{W}}$ were plotted along each chromosome in sliding windows that each included a total of 10,000 sequenced basepairs (Figure 3 ). Differentiation between the species is moderately high across the genome, and most chromosomes show a single broad region of elevated $F_{\text {ST }}$ above a background of lower $F_{\text {ST. }}$ Mean windowed autosomal $F_{\mathrm{ST}}, \pi_{\mathrm{W}}$ and $\pi_{\mathrm{B}}$ for the three species is given in
Table 2. Regions of elevated differentiation tend to have both lower between-population divergence and within-population sequence diversity (Figure 4, Table 2). $F_{\mathrm{ST}}$ shows a trend toward inverse correlation with between-group pairwise nucleotide distance $\pi_{\mathrm{B}}$ (Figure $\mathrm{S} 4$; Pearson's product-moment correlation, $\mathrm{t}=-1.94$, $\mathrm{df}=1159, \mathrm{R}=$ $0.057, \mathrm{p}=0.052$ ). Within-group pairwise nucleotide distance $\pi_{\mathrm{W}}$ is highly inversely correlated with $F_{\mathrm{ST}}$ (as expected given their mathematical relationship) (Figure S5, Table 2). Regions of increased within-population diversity also tend to have greater sequence divergence between species, as $\pi_{\mathrm{W}}$ and $\pi_{\mathrm{B}}$ are highly correlated (Spearman's Rank Correlation, $\mathrm{S}=3.6 \times 10^{7}, \mathrm{r}_{\mathrm{S}}=0.86, \mathrm{p}<2 \times 10^{-16}$ ). The windows of highest $F_{\mathrm{ST}}$ tend to occur at low values of $\pi_{\mathrm{B}}$ and at low values of $\pi_{\mathrm{W}}$ (Figure 4, S4). In summary, we observe moderately high levels of differentiation across the genomes of the Pacific and Winter

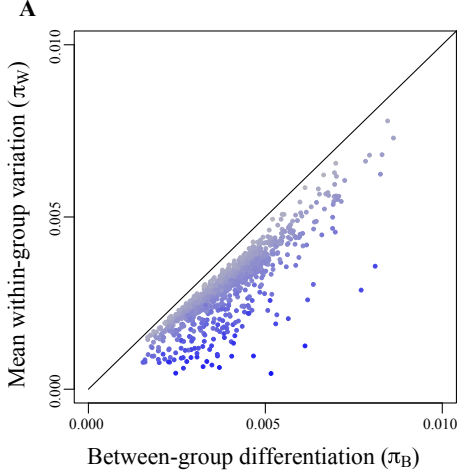

B

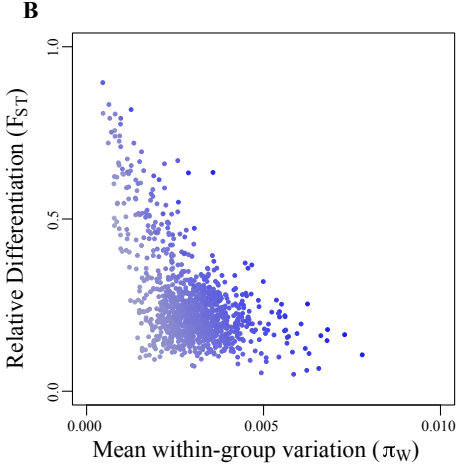

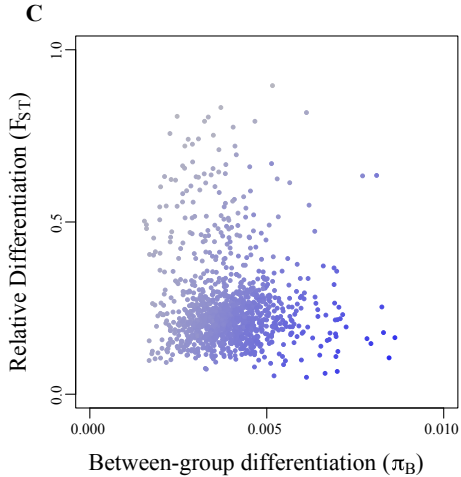

Figure 4. Relationships between $\pi_{\mathrm{B}}$ and mean $\pi_{\mathrm{W}}(\mathbf{A})$, mean $\pi_{\mathrm{W}}$ and $F_{\mathrm{ST}}(\mathbf{B})$, and $\pi_{\mathrm{B}}$ and $F_{\mathrm{ST}}(\mathbf{C})$. Statistics were calculated in sliding windows containing 10,000 bp of genotyped positions. Points are colored to depict the unplotted statistic in each panel: $F_{\text {ST }}$ $(\mathbf{A}), \pi_{\mathrm{B}}(\mathbf{B})$, and $\pi_{\mathrm{W}}(\mathbf{C})$, with values colored from low (grey) to high (blue). 

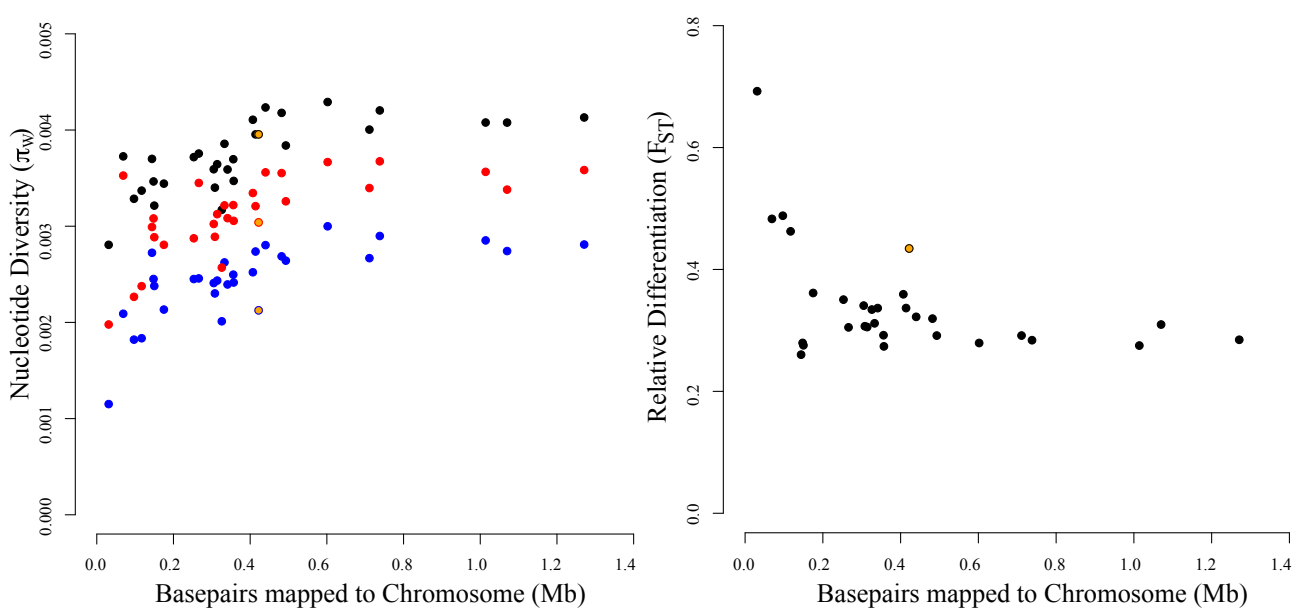

Figure 5. Average $F_{\mathrm{ST}}, \pi_{\mathrm{W}}$, and $\pi_{\mathrm{B}}$ compared to chromosome size. A: $\pi_{\mathrm{B}}$ (black) and $\pi_{\mathrm{W}}$ in Pacific (blue) and Winter Wrens (red) show a positive relationship with chromosome size, and the smallest microchromosomes show the lowest levels of nucleotide diversity. Chromosome size is approximated by the number of sequenced basepairs mapped to each Ficedula chromosome. The $\mathrm{Z}$ chromosome is highlighted in gold. B: The four smallest microchromosomes show the highest $F_{\mathrm{ST}}$, and the $\mathrm{Z}$ chromosome (gold) has elevated $F_{\mathrm{ST}}$ relative to autosomes of a similar size. $F_{\mathrm{ST}}$ was calculated using the Weir \& Cockerham (1984) method for incorporating multiple loci.

Wrens, with the regions of highest differentiation occurring in regions of lower sequence diversity $\left(\pi_{\mathrm{W}}\right)$ and lower absolute sequence divergence $\left(\pi_{\mathrm{B}}\right)$ (Figure 4 , S4, Table 2 ).

Differentiation and nucleotide diversity also show a relationship with the type and size of chromosomes (Figure 5). The $\mathrm{Z}$ chromosome shows elevated $F_{\text {ST }}$ relative to the autosomes ( 0.43 vs 0.31 , Figure $\left.5 \mathrm{~B}\right)$, and lower $\pi_{\mathrm{W}}$ relative to autosomes of a similar size (Figure $5 \mathrm{~A}$ ). Additionally, both $\pi_{\mathrm{W}}$ and $\pi_{\mathrm{B}}$ are positively correlated with chromosome size, with the steepest relationship among the smaller chromosomes (Figure 5A). These smallest microchromosomes also have the highest $F_{\text {ST }}$ (Figure 5B, Table S2).

\section{Translocation from an Autosome to a Sex Chromosome}

Six females (three Pacific Wrens and three Winter Wrens) were identified in this dataset by observing a substantial reduction in apparent heterozygosity of SNPs mapping to the $\mathrm{Z}$ chromosome compared to males (Figure S6) (in birds, females are the heterogametic sex with a $Z$ and $\mathrm{W}$ chromosome, while males have two $\mathrm{Z}$ chromosomes; females thus only appear heterozygous at the small $\mathrm{Z}$ chromosome regions that are homologous with the $\mathrm{W}$ chromosome). Surprisingly, these six females were also outliers on a PCA of SNPs mapping to Ficedula chromosome 8, being widely separated from all males along PC2 (Figure 6A, Figure S2). The probability that all six of the Ficedula chromosome 8 outlier individuals in this dataset would be the six females due to chance is extremely low $\left(p=4.22 \times 10^{-9}\right)$, so it is unlikely that this pattern was not causally related to the sex of the bird. The region of Ficedula chromosome 8 that drives this pattern was identified by analyzing successively smaller segments of the chromosome on PCA, which revealed that the boundaries of the region most likely lay between 17.7-17.8 Mb and between 22.2-22.4 Mb of the Ficedula chromosome 8 assembly. Since these breakpoints lie near the HS2ST1 and OLFM3 genes, we will refer to this segment of Ficedula chromosome 8 as the HS2ST1-OLFM3 region, a roughly $4.5 \mathrm{Mb}$ region containing approximately 74 genes (Table S4).

The separate clustering of males and females on the PCA of the HS2ST1-OLFM3 region could be explained by a translocation of the region from the autosome to a sex chromosome in the ancestral wren lineage. It is unlikely that the translocation occurred in the opposite direction, from the sex chromosome to chromosome 8 in the Ficedula lineage, as gene content in the HS2ST1OLFM3 and flanking regions of chromosome 8 is conserved with more distant outgroups (Table S4).

The present chromosomal location of the HS2ST1-OLFM3 sequence in the wren genome can be determined by examining patterns of heterozygosity and nucleotide diversity. If the HS2ST1-OLFM3 region were translocated or duplicated to a sex chromosome in the wren lineage, then it would be expected that females and males would show a different level of observed heterozygosity. If the HS2ST1-OLFM3 region were translocated only to the $\mathrm{Z}$ chromosome, then males would show a higher apparent heterozygosity than females since males possess two $\mathrm{Z}$ chromosomes. Alternatively, if the HS2ST1-OLFM3 region were duplicated to the $\mathrm{W}$ chromosome, then females would likely show a higher heterozygosity than males due to female-restricted alleles arising on the $\mathrm{W}$ chromosome copy.

Table 3. Average $\pi_{\mathrm{W}}$ in males and females in the translocated region homologous to Ficedula chromosome 8 from $17.79-22.30 \mathrm{Mb}$, as well as upstream and downstream sequences of chromosome 8 , and the $\mathrm{Z}$ chromosome. Females have a higher average $\pi_{\mathrm{w}}$ than males in the translocated region, but comparable $\pi_{\mathrm{W}}$ to males in the chromosome 8 flanking regions and lower $\pi_{\mathrm{W}}$ on the $\mathrm{Z}$ chromosome.

\begin{tabular}{lcccc}
\hline & $\begin{array}{c}\text { Translocated } \\
\text { Region }\end{array}$ & $\begin{array}{c}\text { Chr 8 } \\
\text { Downstream }\end{array}$ & $\begin{array}{c}\text { Chr 8 } \\
\text { Upstream }\end{array}$ & Chr Z \\
\hline Male pacificus & 0.0030 & 0.0027 & 0.0027 & 0.0021 \\
Male hiemalis & 0.0038 & 0.0033 & 0.0030 & 0.0030 \\
Female pacificus & 0.0090 & 0.0024 & 0.0026 & 0.0014 \\
& & & & \\
Female hiemalis & 0.0092 & 0.0029 & 0.0029 & 0.0022 \\
\hline
\end{tabular}

To test which predicted pattern is consistent with the data, we compared the apparent heterozygosity of males and females along Ficedula chromosome 8. In the region from 17.79-22.30 $\mathrm{Mb}$ on Ficedula chromosome 8 (the HS2ST1-OLFM3 region), many loci showed much higher heterozygosity in females than males: females are heterozygous at an average of $25 \%$ (Pacific) or $28 \%$ (Winter) of the SNPs in this region, while males are only heterozygous at $4 \%$ (Pacific) or 3\% (Winter) of the SNPs (similarly, females showed a much higher value for $\pi_{\mathrm{W}}$ (Table 3, Figure 6B)). The elevated female heterozygosity strongly indicates that a copy of the HS2ST1-OLFM3 region is present in a non-recombining region of the $\mathrm{W}$ chromosome, providing allelic diversity that is unique to females. Males still contain sequence reads that map to the HS2ST1-OLFM3 region, indicating that a copy of the sequence either remains on an autosome (chromosome 8) or was also translocated to the $\mathrm{Z}$ chromosome. Estimates of sequence diversity provide a way to differentiate between 1) translocation to the $\mathrm{W}$ and $\mathrm{Z}$ 
A bioRxiv preprint doi: https://doi.org/10.1101/2021.02.09.430089; this version posted February 10, 2021. The copyright holder for this preprint
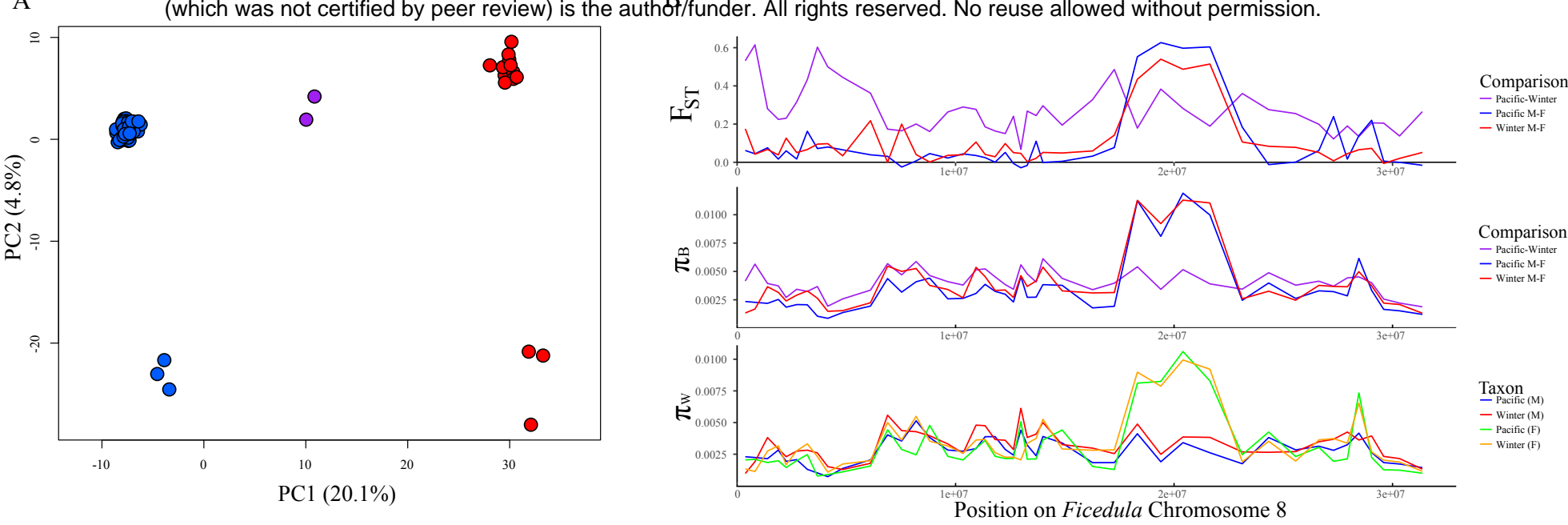

Figure 6. Evidence for a translocation from an autosome to a sex chromosome. A: PCA based on sequences mapping to Ficedula chromosome 8 separate the six females (three Pacific Wrens, in blue; three Winter Wrens, in red) from the males along PC2, which is not an expected pattern for an autosome. B: Scan of $F_{\mathrm{ST}}, \pi_{\mathrm{B}}$, and $\pi_{\mathrm{W}}$ along the sequenced loci mapping to Ficedula chromosome 8, with Pacific and Winter Wrens separated into males and females. A large peak appears in the region around 20 Mb in which females have highly elevated $\pi_{\mathrm{W}}$ relative to males (bottom), and where $F_{\mathrm{ST}}$ (top) and $\pi_{\mathrm{B}}$ (middle) between males and females of the same species is much greater than between males of different species.

chromosomes with loss of the autosomal copy, 2) translocation to the $\mathrm{W}$ and $\mathrm{Z}$ chromosomes with the autosomal copy retained, and 3) translocation only to the $\mathrm{W}$ and not the $\mathrm{Z}$, with the autosomal copy retained.

Under the first scenario (translocation to $\mathrm{Z}$ and $\mathrm{W}$, loss on autosome), males would likely show a lowered $\pi_{\mathrm{W}}$ in the HS2ST1-OLFM3 region compared to other regions of Ficedula chromosome 8 if the translocation event occurred recently, since the translocation event likely involved only a single copy of the sequence lacking any genetic diversity. This pattern is not observed (Figure 6B). However, if this translocation event occurred very far in the past, then subsequent mutations could have restored genetic diversity in the HS2ST1-OLFM3 region. This scenario can be ruled out by comparing the heterozygosity of males and females at loci within the translocated region. If the region were translocated to both the $\mathrm{Z}$ and $\mathrm{W}$ chromosome and lost on the autosome, then females would show a lower heterozygosity than males at the loci that are variable in males. This is because any new derived alleles that arise on the $\mathrm{Z}$ chromosome will have two chances to be found in males with two $Z$ chromosomes, while females will have only one chance to carry the derived Z-linked allele. However, this pattern was not observed: females and males showed similar levels of heterozygosity at the loci that are variable in males $(13.8 \%$ in females, $13.0 \%$ in males).

Under the second scenario (duplication to both the $\mathrm{Z}$ and $\mathrm{W}$ while retained on an autosome), it would be expected that males would have elevated heterozygosity in the HS2ST1-OLFM3 region relative to the background diversity on Ficedula chromosome 8, due to the presence of four rather than two copies of the HS2ST1-OLFM3 region; this is not observed either. Males show a comparable level of heterozygosity within and outside of the translocated region, with males heterozygous at $0.09 \%$ (Pacific Wren) and $0.13 \%$ (Winter Wren) of all loci within the translocated region, compared to $0.11 \%$ and $0.13 \%$ of loci in the remaining regions of Ficedula chromosome 8. These patterns are instead consistent with the third scenario: that the HS2ST1-OLFM3 region has been duplicated only to the $\mathrm{W}$ chromosome while a version of the original autosomal copy has been retained.

\section{Discussion}

In both allopatry and sympatry, Pacific Wrens and Winter Wrens form highly distinct genetic clusters, with an overall genomic $F_{\mathrm{ST}}$ of 0.31 . Together with clear phenotypic differences in song and migratory behavior as well as subtle difference in plumage coloration (Toews \&
Irwin 2008), the evidence in support of them being separate species is strong. The estimated mitochondrial DNA divergence time indicates that these two species started diverging long ago (roughly 4.3 million years ago) compared to many other sister species of birds (Weir \& Schluter, 2004).

Surprisingly given this deep age of divergence between Pacific and Winter Wrens, two first-generation hybrids (i.e., F1 hybrids) were observed within a dataset of 75 wrens, only 22 of which were from the contact zone between the two species. These two observed F1 hybrids were both adult birds who had successfully undergone one cycle of seasonal migration between breeding and wintering grounds, indicating that they are healthy enough to survive these phases of the life cycle. They were found far apart from one another, meaning that they almost certainly are the products of different parental pairs. Hence these F1 hybrids show that premating isolation is far from complete and that F1 hybrids can be healthy.

Despite production and viability of $\mathrm{F} 1$ hybrids, we saw no evidence for recent backcrossing or other reproduction of hybrids, suggesting that F1 hybrids suffer greatly reduced fitness relative to parental birds. The most plausible explanation for our results is that F1 hybrids currently have low (virtually zero) reproductive success. Without strong selection against hybrids, later-generation hybrids should outnumber firstgeneration F1 hybrids given that F1 hybrids are only produced by an initial hybridization event and any of their descendants would be detectable as hybrids for many generations. Determining the reason for low fitness of F1 hybrids will have to await further study, but possibilities include problems with meiosis, behaviors of hybrids that interfere with processes such as seasonal migration (Helbig, 1991; Delmore, Toews, Germain, Owens, \& Irwin, 2016) or mate attraction (Bridle, Saldamando, Koning, \& Butlin, 2006), and physiological problems that interfere with reproduction or cause the offspring of F1 hybrids to be inviable (Hill, 2019).

Despite the lack of evidence for recent gene flow between Pacific and Winter Wrens, we were able to detect some evidence for gene flow in the more distance past. By examining thousands of markers across the genome, it is possible to detect hybridization events from past generations by observing blocks of markers in the genome containing alleles associated with the other species (Alcaide et al., 2014; Lopes et al., 2016; Ravinet et al., 2017; Sedghifar, Brandvain, \& Ralph, 2016; VonHoldt et al., 2011). Only one such block was detected, in a sympatric Winter Wren that is heterozygous for a single $375 \mathrm{~kb}$ Pacific Wren haplotype fragment on chromosome 24. The small block size, 
corresponding to less than $5 \mathrm{cM}$ on the Ficedula genetic map (Kawakami et al., 2014), and absence of similar detectable fragments on other chromosomes strongly suggest that this introgression event occurred many generations in the past.

The finding of only a single block of clear introgression between the two species indicates only a very small amount of introgression in the relatively recent past (e.g., on the order of the past hundred to several thousand generations). More deeply in time, examining the relationship between $F_{\mathrm{ST}}$ and $\pi_{\mathrm{B}}$ can help distinguish between different histories of population isolation and/or gene flow (Cruickshank \& Hahn 2014; Irwin et al. 2016, 2018). The lack of a positive relationship between $F_{\mathrm{ST}}$ and $\pi_{\mathrm{B}}$ leads us to reject a simple model of differentiation with gene flow, in which reproductive incompatibilities protect segments of the genome from gene flow. The slight negative relationship (although not quite significant) suggests a possible role for occasional selective sweeps between the two species, followed by selective differentiation of these regions within each population. Such a history is compatible with the many cycles of glacial and interglacial periods in North America over the past 2 million years, in which incipient Pacific and Winter wren populations could have undergone periods of isolation followed by contact and hybridization. However, the lack of a statistically significant relationship between $F_{\mathrm{ST}}$ and $\pi_{\mathrm{B}}$ does not allow a clear distinguishing of that model from simple differentiation in allopatry, in which a flat relationship between $F_{\mathrm{ST}}$ and $\pi_{\mathrm{B}}$ is expected.

Unlike many brightly-plumaged songbirds, the cryptic plumage and subtle morphological differences that distinguish the Pacific and Winter Wrens appear unlikely to present a significant premating barrier between the species. Instead, song, a learned trait, may be critical for species recognition and mate selection as it is in many other bird species (Kroodsma, Bereson, Byers, \& Minear, 1989; Mason et al., 2017), and consistent song pattern differences have been identified between the two wren species (Kroodsma, 1980; Toews \& Irwin, 2008), although these differences are apparently insufficient to entirely prevent hybridization. Given that a hybrid was found out of only four Winter Wrens (as originally identified in the field) included in our GBS dataset from the sympatric zone, assortative mating may not be strong. Over time, selection against the production of lower-fitness hybrids might drive the evolution of premating barriers (i.e., reinforcement; Dobzhansky 1940; Liou and Price 1994); however, the low density of wrens in the Tumbler Ridge overlap zone may prevent the fixation of assortative mating alleles as these could be swamped by gene flow from regions of allopatry where birds are not subjected to selection against hybridization. With incomplete premating barriers, postmating barriers may be critical in maintaining two distinct species in this system.

Our results provide insight into one curious aspect of the ranges of Pacific and Winter Wrens: both species have large breeding ranges, but only a narrow area of overlap between them. Within and to either side of the area of overlap, both species are found in similar habitat (Toews \& Irwin, 2008). Given the results presented here, we propose that the narrow overlap is due primarily to reproductive interference and hybridization between the two species. If two species have only moderate premating isolation but F1 hybrids have zero or very low fitness, then interbreeding in the area of range overlap will result in a large set of offspring that do not themselves successfully reproduce. This can result in population decline, causing a population sink. Movement of the parental forms into the zone can keep the contact zone from disappearing entirely, but it remains an area of low population density. This is an extreme form of the "tension zone" model of hybrid zones, in which low hybrid fitness and dispersal of the parental forms into the zone results in a narrow hybrid zone that is stable for long periods of time (Barton \& Hewitt, 1989). The fact that such a pattern (narrow overlap, moderate assortative mating, and very low fitness of F1 hybrids) is seen in such an old species pair suggests that such dynamics explain many narrow hybrid zones.

Compared to strong genetic differences between Pacific and Winter Wrens, we observed little variation within each species. Pacific Wrens from the ranges of subspecies $T$. p. pacificus and T. p. salebrosus are not separated by our PCA of this dataset, and only a single SNP showed $F_{\text {ST }}$ above 0.7 between those groups. This suggests that there is little genomic differentiation between the two subspecies, although it is possible that sampling of wrens from farther southeast in the range of $T$. p. salebrosus would reveal more distinct population structure. Phenotypically, $T$. $p$. pacificus are slightly darker and more rufescent than T. p. salebrosus (Burleigh, 1959), a common trend in birds of the humid Pacific Northwest region. These observed differences may be driven by selection on a few genes above an otherwise homogenous genomic background. If a genetically distinct $T$. $p$. salebrosus population exists, it may be restricted farther southeast than currently described.

The $\mathrm{Z}$ chromosome has a higher average between-species differentiation $\left(F_{\mathrm{ST}}\right)$ than autosomes in this dataset, as has been observed in other systems (e.g., Delmore et al., 2015; Oyler-McCance, Cornman, Jones, \& Fike, 2015; Corl \& Ellegren, 2012; reviewed by Irwin, 2018). This pattern appears to be driven by lower $\pi_{\mathrm{W}}$, rather than higher $\pi_{\mathrm{B}}$, on the $\mathrm{Z}$ chromosome relative to autosomes of a similar size (Figure 5A). This lower within-population diversity may be partially attributed to the lower effective population size of the $\mathrm{Z}$ compared to autosomes (Corl \& Ellegren, 2012; Oyler-McCance et al., 2015), and to the possibility of broader and more frequent selective sweeps due to reduced recombination and exposure of recessive mutations in the heterogametic sex (Borge, Webster, Andersson, \& Saetre, 2005).

Interestingly, within-species nucleotide diversity $\left(\pi_{\mathrm{W}}\right)$ is positively correlated with chromosome size, particularly among the smallest microchromosomes (Figure 5), resulting in the smaller chromosomes having higher average between-species differentiation $\left(F_{\mathrm{ST}}\right)$ despite a lower between-species sequence divergence $\left(\pi_{\mathrm{B}}\right)$. The patterns of $\pi_{\mathrm{B}}$ in the wrens contrast with findings of higher sequence divergence between chicken and turkey microchromosomes than between macrochromosomes (Axelsson, Webster, Smith, Burt, \& Ellegren, 2005). The microchromosomes of birds harbour a higher gene density than macrochromosomes (ICGSC, 2004), and it may be that this high gene density has led to stronger and denser background selection or more frequent selective sweeps on the wren microchromosomes, reducing their diversity and leading to faster differentiation. These patterns are consistent with selection on individual loci playing a large role in determining genetic diversity along chromosomes, and they do not match the prediction that microchromosomes should have higher diversity than macrochromosomes based on a positive relationship between recombination rate and sequence diversity (Mugal, Nabholz, \& Ellegren, 2013) and a negative relationship between recombination rate and chromosome size (Megens et al., 2009).

Translocations from autosomes to sex chromosomes have been theorized to facilitate sex-specific expression of genes, which may relieve conflict from sexually antagonistic alleles that are beneficial in one sex while detrimental in the other (Albert \& Otto, 2005; Irwin, 2018; Rice, 1984). So far, a few examples have been discovered of translocations to the avian sex chromosomes, including in Myzomela 
Mikkelsen \& Irwin, 08 Feb 2021 - preprint copy - BioRxiv

honeyeaters (Sardell, 2016), Alauda larks (Brooke et al., 2010), the Sylvioidea songbird superfamily (Pala et al., 2012), and the Eastern Yellow Robin (Gan et al., 2019). In the present study, the $4.5 \mathrm{Mb}$ region duplicated to the wren $\mathrm{W}$ chromosome contains 74 annotated proteincoding genes in the Ficedula chromosome 8 assembly. This represents a substantial addition to the $6.9 \mathrm{Mb}$ non-recombining region of the $\mathrm{W}$ chromosome, which contains only 46 known genes in Ficedula (Smeds et al., 2015). If one of these genes is involved in expressing sexually antagonistic traits, then selection may have favoured a rare duplication of this fragment to the $\mathrm{W}$ chromosome despite the apparently strong selection against most inter-chromosomal translocations. It remains to be determined whether these duplicated genes remain functional, and whether divergence in function has occurred between the $\mathrm{W}$ and autosomal gene copies. These wrens provide a rare opportunity to investigate the relative rates and characteristics of evolution of homologous autosomal and W-chromosomes copies of a large genetic region.

In conclusion, Pacific and Winter Wrens have been differentiating for millions of years and appear to have almost complete lack of current gene flow. They still hybridize at a sizeable rate, but the F1 hybrids apparently have zero or very low fitness. The combination of little to moderate assortative mating with very low fitness of hybrids is expected to result in populations being unable to coexist over a broad region (Barton \& Hewitt, 1989; Goldberg \& Lande, 2007; Irwin, 2020). The Pacific and Winter Wrens provide a particularly difficult-to-detect combination of reproductive isolating dynamics: their similar appearances make hybrids difficult to detect, and the fact that F1 hybrids are viable would make low hybrid fitness difficult to detect directly (both of these were inferred here using genomic analysis). We suspect that similar dynamics are common in many other contact zones between closely-related neighbouring species. If so, the narrowness of hybrid zones is explained well by reproductive interference and these tension zone dynamics. While differentiation in ecological niches and/or niche exclusion are interesting factors, in many cases they may not need to be invoked to explain narrow contact zones. Difficult-todetect production of low-fitness hybrids could provide a large part of the explanation for the general observation that it tends to take many millions of years of differentiation before bird species become broadly sympatric (Price, 2010).

\section{Acknowledgments}

We are grateful to Silu Wang and Armando Geraldes for lab training and support. We also thank Loren Reiseberg, Sally Otto, and Kristin Nurkowski for laboratory support and assistance. We thank David Toews for collecting many of the samples from the Toews and Irwin (2008) study. The Genome Quebec Innovation Centre provided sequencing services. Funding was provided by the Natural Sciences and Engineering Research Council of Canada (grants 311931-2012, RGPIN2017-03919 and RGPAS-2017-507830 to DEI).

\section{Author Contributions and Notes}

E.K.M. and D.E.I. conceived of the project. E.K.M. performed lab work. D.E.I. and E.K.M. ran the bioinformatics pipeline. E.K.M. analyzed the data and D.E.I. provided guidance. E.K.M and D.E.I. wrote the paper.

\section{Data Accessibility}

Prior to publication, DNA sequencing reads will be deposited to the NCBI Sequence Read Archive. Genotype data and R code associated with the PCA, $F_{\mathrm{ST}}, \pi_{\mathrm{W}}$, and $\pi_{\mathrm{B}}$ analyses will be deposited in Dryad and available in a Github repository

(https://github.com/elsemikk/Wren_popgen).

\section{References}

Albert, A. Y. K., \& Otto, S. P. (2005). Sexual selection can resolve sexlinked sexual antagonism. Science, 310(5745), 119-121.

Alcaide, M., Scordato, E. S. C., Price, T. D., \& Irwin, D. E. (2014). Genomic divergence in a ring species complex. Nature, 511, 8385. doi: 10.1038 /nature 13285

Axelsson, E., Smith, N. G. C., Sundström, H., Berlin, S., \& Ellegren, H. (2004). Male-biased mutation rate and divergence in autosomal, Z-linked and W-linked introns of chicken and turkey. Molecular Biology and Evolution, 21(8), 1538-1547. doi: $10.1093 / \mathrm{molbev} / \mathrm{msh} 157$

Axelsson, E., Webster, M. T., Smith, N. G. C., Burt, D. W., \& Ellegren, H. (2005). Comparison of the chicken and turkey genomes reveals a higher rate of nucleotide divergence on microchromosomes than macrochromosomes. Genome Research, 15, 120-125. doi: 10.1101/gr.3021305

Baldassarre, D. T., White, T. A., Karubian, J., \& Webster, M. S. (2014). Genomic and morphological analysis of a semipermeable avian hybrid zone suggests asymmetrical introgression of a sexual signal. Evolution, 68(9), 2644-2657. doi: 10.1111/evo.12457

Barker, F. K. (2017). Molecular phylogenetics of the wrens and allies (Passeriformes: Certhioidea), with comments on the relationships of Ferminia. American Museum Novitates, 3887, 1-28.

Barton, N. H., \& Hewitt, G. M. (1989). Adaptation, speciation and hybrid zones. Nature, 341, 497-503.

Bensch, S., Andersson, T., \& Akesson, S. (1999) Morphological and molecular variation across a migratory divide in Willow Warblers, Phylloscopus trochilus. Evolution, 53, 1925-1935.

Bolger, A. M., Lohse, M., \& Usadel, B. (2014). Trimmomatic: A flexible trimmer for Illumina sequence data. Bioinformatics, 30(15), 2114-2120. doi: 10.1093/bioinformatics/btu170

Borge, T., Webster, M. T., Andersson, G., \& Saetre, G. P. (2005). Contrasting patterns of polymorphism and divergence on the $\mathrm{Z}$ chromosome and autosomes in two Ficedula flycatcher species. Genetics, 171(4), 1861-1873. doi: 10.1534/genetics.105.045120

Brelsford, A., \& Irwin, D. E. (2009). Incipient speciation despite little assortative mating: The yellow-rumped warbler hybrid zone. Evolution, 63(12), 3050-3060. doi: 10.1111/j.15585646.2009.00777.x

Bridle, J. R., Saldamando, C. I., Koning, W., \& Butlin, R. K. (2006). Assortative preferences and discrimination by females against hybrid male song in the grasshoppers Chorthippus brunneus and Chorthippus jacobsi (Orthoptera: Acrididae). Journal of Evolutionary Biology, 19, 1248-1256.

Brooke, M. de L., Welbergen, J. A., Mainwaring, M. C., Van der Velde, M., Harts, A. M. F., Komdeur, J., \& Amos, W. (2010). Widespread translocation from autosomes to sex chromosomes preserves genetic variability in an endangered lark. Journal of Molecular Evolution, 70(3), 242-246. doi: 10.1007/s00239-0109333-3

Burleigh, T. D. (1959). Two new subspecies of birds from Western North America. Proceedings of the Biological Society of Washington, 72(5), 15-18.

Chesser, R. T., Banks, R. C., Barker, F. K., Cicero, C., Dunn, J. L., Kratter, A. W., ... Winker, K. (2010). Fifty-first Supplement to the American Ornithologists' Union Check-list of North American Birds. The Auk, 127(3), 726-744. doi: 10.1642/AUK16-77.1

Consortium, I. C. G. S. (2004). Sequence and comparative analysis of 
bioRxiv preprint doi: https://doi.org/10.1101/2021.02.09.430089; this version posted February 10, 2021. The copyright holder for this preprint (which was not certified by peer review) is the author/funder. All rights reserved. No reuse allowed without permission.

Mikkelsen \& Irwin, 08 Feb 2021 - preprint copy - BioRxiv

the chicken genome provide unique perspectives on vertebrate evolution. Nature, 432, 695-777. doi: 10.1017/CBO9781107415324.004

Corl, A., \& Ellegren, H. (2012). The genomic signature of sexual selection in the genetic diversity of the sex chromosomes and autosomes. Evolution, 66(7), 2138-2149. doi: 10.1111/j.15585646.2012.01586.x

Cruickshank, T. E., \& Hahn, M. W. (2014). Reanalysis suggests that genomic islands of speciation are due to reduced diversity, not reduced gene flow. Molecular Ecology, 23(13), 3133-3157. doi: 10.1111/mec.12796

Danecek, P., Auton, A., Abecasis, G., Albers, C. A., Banks, E., DePristo, M. A., ... Durbin, R. (2011). The variant call format and VCFtools. Bioinformatics, 27(15), 2156-2158. doi: 10.1093/bioinformatics/btr330

Delmore, K. E., Hübner, S., Kane, N. C., Schuster, R., Andrew, R. L., Câmara, F., ... Irwin, D. E. (2015). Genomic analysis of a migratory divide reveals candidate genes for migration and implicates selective sweeps in generating islands of differentiation. Molecular Ecology, 24(8), 1873-1888. doi: $10.1111 / \mathrm{mec} .13150$

Delmore, K. E., Toews, D. P. L., Germain, R. R., Owens, G. L., \& Irwin, D. E. (2016). The genetics of seasonal migration and plumage color. Current Biology, 26, 2167-2173. doi: 10.1016/j.cub.2016.06.015

Dobzhansky, T. (1940). Speciation as a stage in evolutionary divergence. The American Naturalist, 74, 312-321.

Drovetski, S. V, Zink, R. M., Rohwer, S., Fadeev, I. V, Nesterov, E. V, Karagodin, I., ... Red'kin, Y. a. (2004). Complex biogeographic history of a Holarctic passerine. Proceedings: Biological Sciences, 271(1538), 545-551. doi: 10.1098/rspb.2003.2638

Earl, D. A., \& vonHoldt, B. M. (2012). STRUCTURE HARVESTER: A website and program for visualizing STRUCTURE output and implementing the Evanno method. Conservation Genetics Resources, 4(2), 359-361. doi: 10.1007/s12686-011-9548-7

Ellegren, H., Smeds, L., Burri, R., Olason, P. I., Backström, N., Kawakami, T., ... Wolf, J. B. W. (2012). The genomic landscape of species divergence in Ficedula flycatchers. Nature, 491, 756760. doi: $10.1038 /$ nature 11584

Elshire, R. J., Glaubitz, J. C., Sun, Q., Poland, J. A., Kawamoto, K., Buckler, E. S., \& Mitchell, S. E. (2011). A robust, simple genotyping-by-sequencing (GBS) approach for high diversity species. PLoS ONE, 6(5), 1-10. doi: 10.1371/journal.pone.0019379

Evanno, G., Regnaut, S., \& Goudet, J. (2005). Detecting the number of clusters of individuals using the software STRUCTURE: A simulation study. Molecular Ecology, 14(8), 2611-2620. doi: 10.1111/j.1365-294X.2005.02553.x

Gan, H. M., Falk, S., Morales, H. E., Austin, C. M., Sunnucks, P., \& Pavlova, A. (2019). Genomic evidence of neo-sex chromosomes in the eastern yellow robin. GigaScience, 8(9), 1-10.

Gomez, J. E. M., Barber, B. R., \& Peterson, A. T. (2005). Phylogenetic position and generic placement of the Socorro Wren (Thryomanes sissonii). The Auk, 122(1), 50-56.

Goodwin, S., McPherson, J. D., \& McCombie, W. R. (2016). Coming of age: Ten years of next-generation sequencing technologies. Nature Reviews Genetics, 17, 333-351.

Grant, P. R., \& Grant, B. R. (1997). Genetics and the origin of bird species. Proceedings of the National Academy of Sciences of the USA, 94, 7768-7775.

Gröning, J., \& Hochkirch, A. (2008). Reproductive interference between animal species. Quarterly Review of Biology, 83(3),
257-282.

Heather, J. M., \& Chain, B. (2016). The sequence of sequencers: The history of sequencing DNA. Genomics, 107, 1-8. doi: 10.1016/j.ygeno.2015.11.003

Helbig, A. J. (1991). SE- and SW- migrating blackcap (Sylvia atricapilla) populations in Central Europe: Orientation of birds in the contact zone. Journal of Evolutionary Biology, 4, 657-670.

Hill, G. E. (2019). Mitonuclear Ecology. Oxford University Press, Oxford.

Huson, D. H., \& Bryant, D. (2006). Application of phylogenetic networks in evolutionary studies. Molecular Biology and Evolution, 23(2), 254-267. doi: 10.1093/molbev/msj030

Irwin, D. E. (2018). Sex chromosomes and speciation in birds and other ZWsystems. Molecular Ecology, 27(19), 3831-3851.

Irwin, D. E. (2020). Assortative mating in hybrid zones is remarkably ineffective in promoting speciation. American Naturalist, 195 , E150-E167.

Irwin, D. E., Alcaide, M., Delmore, K. E., Irwin, J. H., \& Owens, G. L. (2016). Recurrent selection explains parallel evolution of genomic regions of high relative but low absolute differentiation in a ring species. Molecular Ecology, 25(18), 4488-4507. doi: $10.1111 / \mathrm{mec} .13792$

Irwin, D. E., \& Irwin, J. H. (2005). Siberian migratory divides: The role of seasonal migration in speciation. In R. Greenberg \& P. P. Marra (Eds.), Birds of two worlds: The ecology and evolution of migration (pp. 27-40). Baltimore, Maryland: Johns Hopkins University Press.

Irwin, D. E., Milá, B., Toews, D. P. L., Brelsford, A., Kenyon, H. L., Porter, A. N., ... Irwin, J. H. (2018). A comparison of genomic islands of differentiation across three young avian species pairs. Molecular Ecology, 27(23), 4839-4855. doi: 10.1111/mec.14858

Jakobsson, M., \& Rosenberg, N. A. (2007). CLUMPP: A cluster matching and permutation program for dealing with label switching and multimodality in analysis of population structure. Bioinformatics, 23(14), 1801-1806. doi: 10.1093/bioinformatics/btm233

Kawakami, T., Smeds, L., Backstrom, N., Husby, A., Qvarnstrom, A., Mugal, C. F., ... Ellegren, H. (2014). A high-density linkage map enables a second-generation collared flycatcher genome assembly and reveals the patterns of avian recombination rate variation and chromosomal evolution. Molecular Ecology, 23(16), 4035-4058. doi: 10.1111/mec.12810

Kenyon, H. L., Alcaide, M., Toews, D. P. L., \& Irwin, D. E. (2016). Cultural isolation is greater than genetic isolation across an avian hybrid zone. Journal of Evolutionary Biology, 30(1), 81-95. doi: 10.1111/jeb.12989

Kroodsma, D. E. (1980). Winter Wren singing behavior: A pinnacle of song complexity. The Condor, 82(4), 357-365.

Kroodsma, D. E., Bereson, R. C., Byers, B. E., \& Minear, E. (1989). Use of song types by the Chestnut-sided Warbler: evidence for both intra- and inter-sexual functions. Canadian Journal of Zoology, 67(2), 447-456. doi: 10.1139/z89-065

Kroodsma, D. E., \& Momose, H. (1991). Songs of the Japanese population of the Winter Wren (Troglodytes troglodytes). The Condor, 93(2), 424-432.

Lee-Yaw, J. A., \& Irwin, D. E. (2015). The importance (or lack thereof) of niche divergence to the maintenance of a northern species complex: the case of the long-toed salamander (Ambystoma macrodactylum Baird). Journal of Evolutionary Biology, 28(4), 917-930.

Li, H., \& Durbin, R. (2009). Fast and accurate short read alignment with Burrows-Wheeler transform. Bioinformatics, 25(14), 1754-1760. 
doi: 10.1093/bioinformatics/btp324

Li, H., Handsaker, B., Wysoker, A., Fennell, T., Ruan, J., Homer, N., ... Durbin, R. (2009). The Sequence Alignment/Map format and SAMtools. Bioinformatics, 25(16), 2078-2079. doi: 10.1093/bioinformatics/btp352

Liou, L. W., \& Price, T. D. (1994). Speciation by reinforcement of premating isolation. Evolution, 48, 1451-1459.

Lipshutz, S. E., Overcast, I. A., Hickerson, M. J., Brumfield, R. T., \& Derryberry, E. P. (2017). Behavioural response to song and genetic divergence in two subspecies of white-crowned sparrows (Zonotrichia leucophrys). Molecular Ecology, 26(11), 30113027. doi: $10.1111 / \mathrm{mec} .14002$

Lopes, R. J., Johnson, J. D., Toomey, M. B., Ferreira, M. S., Araújo, P. M., Melo-Ferreira, J., ... Carneiro, M. (2016). Genetic basis for red coloration in birds. Current Biology, 26(11), 1427-1434. doi: 10.1016/j.cub.2016.03.076

Mann, N. I., Barker, F. K., Graves, J. A., Dingess-Mann, K. A., \& Slater, P. J. B. (2006). Molecular data delineate four genera of "Thryothorus" wrens. Molecular Phylogenetics and Evolution, 40(3), 750-759. doi: 10.1016/j.ympev.2006.04.014

Mason, N. A., Burns, K. J., Tobias, J. A., Claramunt, S., Seddon, N., \& Derryberry, E. P. (2017). Song evolution, speciation, and vocal learning in passerine birds. Evolution, 71(3), 786-796. doi: 10.1111/evo.13159

Mason, N. A., \& Taylor, S. A. (2015). Differentially expressed genes match bill morphology and plumage despite largely undifferentiated genomes in a Holarctic songbird. Molecular Ecology, 24(12), 3009-3025. doi: 10.1111/mec.13140

Mayr, E. (1942). Systematics and the origin of species. Dover, New York.

McKenna, A., Hanna, M., Banks, E., Sivachenko, A., Cibulskis, K., Kernytsky, A., ... DePristo, M. A. (2010). The Genome Analysis Toolkit: A MapReduce framework for analyzing next-generation DNA sequencing data. Genome Research, 20, 1297-1301. doi: 10.1101/gr.107524.110.20

Megens, H. J., Crooijmans, R. P. M. A., Bastiaansen, J. W. M., Kerstens, H. H. D., Coster, A., Jalving, R., ... Groenen, M. A. M. (2009). Comparison of linkage disequilibrium and haplotype diversity on macro- and microchromosomes in chicken. BMC Genetics, 10, 1-11. doi: 10.1186/1471-2156-10-86

Morales, H. E., Pavlova, A., Amos, N., Major, R., Kilian, A., Greening, C., \& Sunnucks, P. (2018). Concordant divergence of mitogenomes and a mitonuclear gene cluster in bird lineages inhabiting different climates. Nature Ecology \& Evolution, 2, 1258-1267. doi: 10.1101/095596

Mugal, C. F., Nabholz, B., \& Ellegren, H. (2013). Genome-wide analysis in chicken reveals that local levels of genetic diversity are mainly governed by the rate of recombination. $B M C$ Genomics, 14(1). doi: 10.1186/1471-2164-14-86

Nosil, P. (2008). Speciation with gene flow could be common. Molecular Ecology, 17(9), 2103-2106.

Oyler-McCance, S. J., Cornman, R. S., Jones, K. L., \& Fike, J. A. (2015). Z chromosome divergence, polymorphism and relative effective population size in a genus of lekking birds. Heredity, 115(5), 452-459. doi: 10.1038/hdy.2015.46

Pala, I., Naurin, S., Stervander, M., Hasselquist, D., Bensch, S., \& Hansson, B. (2012). Evidence of a neo-sex chromosome in birds. Heredity, 108(3), 264-272. doi: 10.1038/hdy.2011.70

Payseur, B. A., \& Rieseberg, L. H. (2016). A genomic perspective on hybridization and speciation. Molecular Ecology, 25(11), 23372360. doi: $10.1111 / \mathrm{mec} .13557$

Price, T. (2008). Speciation in birds. Roberts, Greenwood Village, CO.
Price, T. (2010). The roles of time and ecology in the continental radiation of the Old World leaf warblers (Phylloscopus and Seicercus). Philosophical Transactions of the Royal Society of London B, 365, 1749-1762.

Price, T. D., \& Kirkpatrick, M. (2009). Evolutionarily stable range limits set by interspecific competition. Proceedings of the Royal Society B: Biological Sciences, 276, 1429-1434.

R Core Team. (2018). R: A language and environment for statistical computing. Vienna, Austria: $\mathrm{R}$ Foundation for Statistical Computing.

Ravinet, M., Faria, R., Butlin, R. K., Galindo, J., Bierne, N., Rafajlović, M., ... Westram, A. M. (2017). Interpreting the genomic landscape of speciation: a road map for finding barriers to gene flow. Journal of Evolutionary Biology, 30(8), 1450-1477. doi: 10.1111/jeb. 13047

Rice, W. R. (1984). Sex chromosomes and the evolution of sexual dimorphism. Evolution, 38(4), 735-742.

Rosenberg, N. A. (2004). DISTRUCT: A program for the graphical display of population structure. Molecular Ecology Notes, 4(1), 137-138. doi: 10.1046/j.1471-8286.2003.00566.x

Sardell, J. M. (2016). Evolutionary consequences of recent secondary contact between Myzomela honeyeaters. Open Access Dissertations, 1591, 1-148.

Schumer, M., Powell, D. L., Delclós, P. J., Squire, M., Cui, R., Andolfatto, P., \& Rosenthal, G. G. (2017). Assortative mating and persistent reproductive isolation in hybrids. Proceedings of the National Academy of Sciences of the USA, 114, 1093610941.

Sedghifar, A., Brandvain, Y., \& Ralph, P. (2016). Beyond clines: Lineages and haplotype blocks in hybrid zones. Molecular Ecology, 25(11), 2559-2576. doi: 10.1111/mec.13677

Seutin, G., White, B. N., \& Boag, P. T. (1991). Preservation of avian blood and tissue samples for DNA analyses. Canadian Journal of Zoology, 69(1), 82-90.

Smeds, L., Qvarnström, A., \& Ellegren, H. (2016). Direct estimate of the rate of germline mutation in a bird. Genome Research, 26(9), 1211-1218. doi: 10.1101/gr.204669.116

Smeds, L., Warmuth, V., Bolivar, P., Uebbing, S., Burri, R., Suh, A., ... Ellegren, H. (2015). Evolutionary analysis of the female-specific avian W chromosome. Nature Communications, 6(7330), 1-10. doi: $10.1038 /$ ncomms 8330

Stacklies, W., Redestig, H., Scholz, M., Walther, D., \& Selbig, J. (2007). pcaMethods - A bioconductor package providing PCA methods for incomplete data. Bioinformatics, 23(9), 1164-1167. doi: 10.1093/bioinformatics/btm069

Stephens, M. M., Pritchard, J. K., \& Donnelly, P. (2000). Inference of population structure using multilocus genotype data. Genetics, 155(2), 945-959. doi: 10.1111/j.1471-8286.2007.01758.x

Stryjewski, K. F., \& Sorenson, M. D. (2017). Mosaic genome evolution in a recent and rapid avian radiation. Nature Ecology and Evolution, 1(12), 1912-1922.

Toews, D. P. L., \& Irwin, D. E. (2008). Cryptic speciation in a Holarctic passerine revealed by genetic and bioacoustic analyses. Molecular Ecology, 17(11), 2691-2705. doi: 10.1111/j.1365294X.2008.03769.x

Toews, D. P. L., Taylor, S. A., Vallender, R., Brelsford, A., Butcher, B. G., Messer, P. W., \& Lovette, I. J. (2016). Plumage genes and little else distinguish the genomes of hybridizing warblers. Current Biology, 26(17), 2313-2318. doi: 10.1016/j.cub.2016.06.034

VonHoldt, B. M., Pollinger, J. P., Earl, D. A., Knowles, J. C., Boyko, A. R., Parker, H., ... Wayne, R. K. (2011). A genome-wide 
bioRxiv preprint doi: https://doi.org/10.1101/2021.02.09.430089; this version posted February 10, 2021. The copyright holder for this preprint (which was not certified by peer review) is the author/funder. All rights reserved. No reuse allowed without permission.

perspective on the evolutionary history of enigmatic wolf-like canids. Genome Research, 21(8), 1294-1305. doi: $10.1101 /$ gr.116301.110

Warren, W. C., Clayton, D. F., Ellegren, H., Arnold, A. P., Hillier, L. W., Künstner, A., ... Wilson, R. K. (2010). The genome of a songbird. Nature, 464(7289), 757-762. doi: 10.1038/nature08819

Weir, B. S., \& Cockerham, C. C. (1984). Estimating F-Statistics for the analysis of population structure. Evolution, 38(6), 1358-1370.

Weir, J. T., \& Schluter, D. (2004). Ice sheets promote speciation in
Mikkelsen \& Irwin, 08 Feb 2021 - preprint copy - BioRxiv

boreal birds. Proceedings of the Royal Society of London B, 271, 1881-1887. doi:10.1098/rspb.2004.2803

Weir, J. T., \& Schluter, D. (2008). Calibrating the avian molecular clock. Molecular Ecology, 17(10), 2321-2328. doi: 10.1111/j.1365-294X.2008.03742.X

Weir, J. T., \& Schluter, D. (2007). The latitudinal gradient in recent speciation and extinction rates of birds and mammals. Science, 315(5818), 1574-1576. doi: 10.1126/science. 1135590 